\title{
EDITORIAL
}

\section{Leptospirosis: one of the forgotten diseases}

\author{
Leandro U. Taniguchi ${ }^{1,2,3^{*}}$ (] and Pedro Póvoa ${ }^{4,5,6}$ (B)
}

C 2019 Springer-Verlag GmbH Germany, part of Springer Nature

"On a strange, acute infectious disease, accompanied by swelling of the spleen, icterus, and nephritis" Adolf Weil (1886)

Leptospirosis is a zoonosis with a worldwide distribution affecting in particular countries with tropical and subtropical climates. Even before the first description of leptospirosis by Adolf Weil in 1886, the disease was well known in different parts of the world frequently with names, some of which associated with agriculture or industrial activities [1]. Leptospira, a corkscrew shaped bacterium, was first identified in 1907, but it was only in 1915 that this bacteria was recognized as the cause of this disease by Inada and Ido in Japan [2].

Leptospires are Gram-negative aerobic bacteria from the order Spirochaetales and the family Leptospiraceae, comprising 26 serogroups and more than 260 serovars [3]. Although several mammals have been identified as potential reservoirs, the rats are the most significant one. The pathogenesis of the disease is poorly understood [4], but to develop leptospirosis the bacteria has to reach the host after contact or drinking contaminated water through small abrasions in the skin or the mucosa of the conjunctiva, oro and nasopharynx. Subsequently, it multiplies and grows spreading to virtually all organs causing a systemic infection. The disease is more frequent in tropical countries (10-100 per 100,000 inhabitants) compared to non-tropical areas (0.1-1 per 100,000 inhabitants). However, it is present in all continents with the exception of Antarctica [5, 6]. In Europe the number of reported cases was 1222 in 2015, that represents an increase in relation to the average reported cases in the 5 years before [7]. However, climate change and global

\footnotetext{
*Correspondence: leandro.taniguchi@gmail.com

1 Emergency Medicine Discipline, Hospital das Clínicas HCFMUSP,

Faculdade de Medicina, Universidade de Sao Paulo, Av Enéas de Carvalho Aguiar 255 Sala 5023, São Paulo 05403-000, Brazil

Full author information is available at the end of the article
}

warming could alter this scenario in Europe with more favorable conditions of transmission. In addition, it is clear that leptospirosis is re-emerging in some countries [4].

Leptospirosis could present itself as a very severe disease, with multiple organ dysfunction with unusual clinical phenotypes (e.g. pulmonary failure with alveolar hemorrhage or marked jaundice without liver failure). Since in non-tropical areas it is an uncommon reason of hospital admission, clinicians often miss this diagnosis. Therefore, incidence in non-endemic areas is unknown and, more clinically relevant, misdiagnosis might occur. In this issue, Miailhe et al. [8] report the largest cohort of severe leptospirosis cases requiring intensive care unit (ICU) admission in a French multicenter cohort. During a 4-year period (2012-2016), 160 patients were retrospectively identified $(0.04 \%$ of all ICU admissions). Overall hospital mortality was surprisingly low (9\%) if one considers the severity-ofillness score (median SAPS II of 40) and the high prevalence of organ failures (SOFA of 11, more than half on vasoactive drugs, and at least one-third on invasive mechanical ventilation or renal replacement therapy). Multiple correspondence analysis and hierarchical classification on principal components identified four clinical phenotypes, with different prevalence and clinical presentations, and more relevant, contrasting demand for organ support therapies and mortality rates. Their phenotyping is mostly welcomed because it is based on clinical characteristics readily available and highlights the heterogeneity of this disease, and might help clinicians to raise clinical suspicious and pursuit proper microbiological diagnosis as well as initiate adequate antibiotic treatment empirically.

However, we believe that one of the major strengths of this study is that it portends a relevant observation in critical care medicine: the same disease might have strikingly different mortality rates throughout the world. The authors mentioned this briefly in the

\section{Springer}



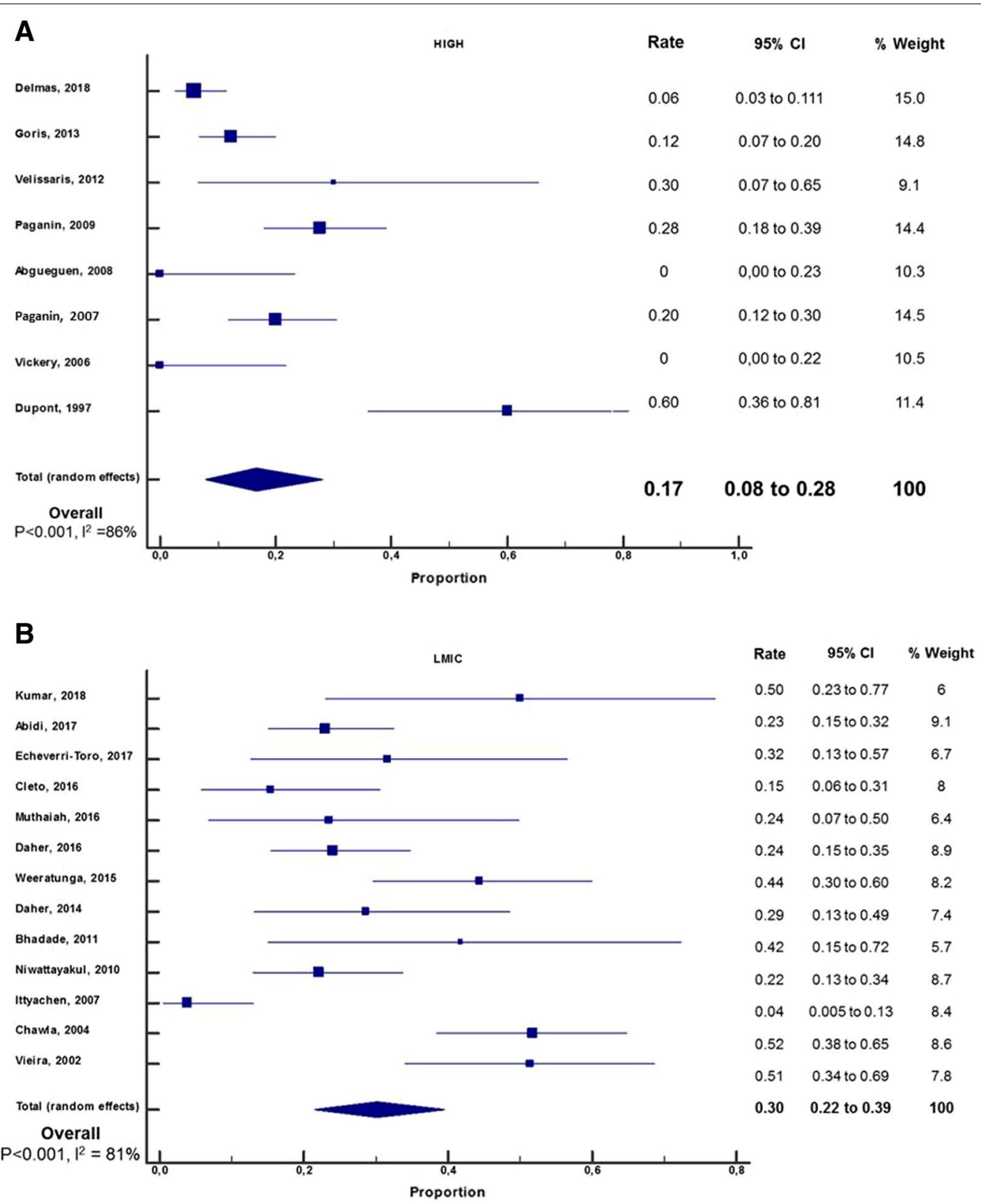

Fig. 1 Forest plots showing a pooled mortality rate of studies from high-income countries (HIC) and b pooled mortality rate of studies from lowmiddle-income countries (LMIC)

discussion, but the tropical vs non-tropical labels do not explain the issue entirely. This geographical view hinders another relevant classification: high income (HIC) vs low-middle income countries (LMIC). A search in Pubmed found 21 previous publications about cases of leptospirosis in ICU (reports with at least ten patients with leptospirosis, see Supplementary Appendix for details). The pooled mortality rate was $25 \%$ (95\% CI $18-33 \%)$, but higher for LMICs (30\%, with $95 \%$ CI of $22-39 \%)$ compared to HIC (17\%, with $95 \%$ CI of $8-28 \%$,
Fig. 1). With the present study, this discrepancy in mortality rates even increases. Although distinct serovars might explain some of these differences, certainly climate and geographic location might not. A recent publication from Reunion Island (a French department located in the Indian Ocean, a tropical area) reports in 134 ICU patients a mortality rate of $6 \%$ [9]. Healthcare resources are not different between Reunion Island and continental mainland, but probably different compared to LMICs. 
Since severe leptospirosis is a cause of sepsis (i.e. infection with organ dysfunction), lower availability of treatment resources are detrimental and unfortunately common in LMICs $[10,11]$. The present study from Miailhe et al. reinforce that leptospirosis, albeit uncommon in some parts of the world, can have good outcomes if properly treated, but much worse outcomes in other areas with treatment resource limitations.

\section{Electronic supplementary material}

The online version of this article (https://doi.org/10.1007/s00134-019-05839-z) contains supplementary material, which is available to authorized users.

\section{Author details \\ ${ }^{1}$ Emergency Medicine Discipline, Hospital das Clínicas HCFMUSP, Faculdade de Medicina, Universidade de Sao Paulo, Av Enéas de Carvalho Aguiar 255 Sala 5023, São Paulo 05403-000, Brazil. ${ }^{2}$ Hospital Sirio Libanes, São Paulo, Brazil. \\ ${ }^{3}$ Brazilian Research in Intensive Care Network (BRICNet), São Paulo, Brazil. \\ ${ }^{4}$ Polyvalent Intensive Care Unit, São Francisco Xavier Hospital, Centro Hos- pitalar de Lisboa Ocidental, Lisbon, Portugal. ${ }^{5}$ NOVA Medical School, CHRC, New University of Lisbon, Lisbon, Portugal. ${ }^{6}$ Center for Clinical Epidemiology and Research Unit of Clinical Epidemiology, OUH Odense University Hospital, Odense, Denmark.}

\section{Compliance with ethical standards}

\section{Conflicts of interest}

The authors declare that they have no conflict of interest.

\section{Publisher's Note}

Springer Nature remains neutral with regard to jurisdictional claims in published maps and institutional affiliations.
Received: 9 October 2019 Accepted: 22 October 2019

Published online: 4 November 2019

\section{References}

1. Adler B (2015) History of leptospirosis and leptospira. Curr Top Microbiol Immunol 387:1-9

2. Kobayashi Y (2001) Discovery of the causative organism of Weil's disease: historical view. J Infect Chemother 7:10-15

3. Levett PN (2001) Leptospirosis. Clin Microbiol Rev 14:296-326

4. Palaniappan RU, Ramanujam S, Chang YF (2007) Leptospirosis: pathogenesis, immunity, and diagnosis. Curr Opin Infect Dis 20:284-292

5. Pavli A, Maltezou HC (2008) Travel-acquired leptospirosis. J Travel Med 15:447-453

6. World Health Organization. Leptospirosis Burden Epidemiology Reference Group (2019) http://www.whogis.com/zoonoses/diseases/lerg/en/ index2.html Accessed 05 Oct 2019

7. European Centre for Disease Prevention and Control (2018) Leptospirosis. ECDC. Annual epidemiological report for 2015. ECDC, Stockholm

8. Miailhe AF, Mercier E, Maamar A, Lacherade JC, Le Thuaut A, Gaultier A (2019) Severe leptospirosis in non-tropical areas: a nationwide, multicentre, retrospective study in French ICUs. Intensive Care Med. https://doi. org/10.1007/s00134-019-05808-6

9. Delmas B, Jabot J, Chanareille P, Ferdynus C, Allyn J, Allou N, Raffray L, Gauzere BA, Martinet O, Vandroux D (2018) Leptospirosis in ICU: a retrospective study of 134 consecutive admissions. Crit Care Med 46:93-99

10. Machado FR, Cavalcanti AB, Bozza FA, Ferreira EM, Angotti Carrara FS, Sousa JL, Caixeta N, Salomao R, Angus DC, Pontes Azevedo LC (2017) The epidemiology of sepsis in Brazilian intensive care units (the Sepsis Prevalence Assessment Database, SPREAD): an observational study. Lancet Infect Dis 17:1180-1189

11. Taniguchi LU, Azevedo LCP, Bozza FA, Cavalcanti AB, Ferreira EM, Carrara FSA, Sousa JL, Salomao R, Machado FR (2019) Availability of resources to treat sepsis in Brazil: a random sample of Brazilian institutions. Rev Bras Ter Intensiva 31:193-201 